\title{
A Novel Design of a Microstrip Microwave Power Amplifier for DCS Application using Collector-Feedback Bias
}

\author{
Amine Rachakh ${ }^{1}$, Larbi El Abdellaoui ${ }^{2}$, Jamal Zbitou $^{3}$, Ahmed Errkik $^{4}$, Abdelali Tajmouati, \\ Mohamed Latrach ${ }^{6}$ \\ ${ }^{1,2,3,4,5}$ LMEET Laboratory FST of Settat Hassan1st University, Morocco \\ ${ }^{6}$ Microwave Group ESEO Angers France
}

\section{Article Info}

Article history:

Received Feb 18, 2018

Revised May 11, 2018

Accepted May 18, 2018

Keyword:

Advanced design system

Bipolar junction transistors

Matching network (MN)

Microstriptechnology

Power amplifier (PA)

\begin{abstract}
This paper presents a $1.80 \mathrm{GHz}$ class-A Microwave power amplifier (PA). The proposed power amplifier is designed with single-stage architecture. This power amplifier consists of a bipolar transistor and improved by Collector-Feedback Biasing fed with a single power supply. The aim of this work is to improve the performance of this amplifier by using simple stubs with $50 \Omega$ microstrip transmissions lines. The proposed PA is investigated and optimized by utilizing Advanced Design System (ADS) software. The simulation results show that the amplifier achieves a high power gain of $13 \mathrm{~dB}$, output power rise up to $21 \mathrm{dBm}$ and good impedances matching ; For the input reflection coefficient (S11) is below than - 46.39dB. Regarding the output reflection coefficient (S22) is below than $-29.898 \mathrm{~dB}$, with an overall size of about $93 \times 59 \mathrm{~mm}^{2}$. By the end; we find that this power amplifier offers an excellent performance for DCS applications.
\end{abstract}

Copyright $\odot 2018$ Institute of Advanced Engineering and Science. All rights reserved.

\section{Corresponding Author:}

Amine Rachakh,

Faculty of Sciences and Techniques,

University Hassan 1st,

University Complex Casablanca road, Km 3.5, B.P: 577 Settat, Morocco.

Email: rachakh.amine1@gmail.com

\section{INTRODUCTION}

BiCMOS, GaAs (Gallium Arsenide) and CMOS are some of the dominant technologies used for radio frequency and microwave circuits. These technologies suggest excellent quality of monolithic capacitors and inductors, lower substrate loss and higher breakdown voltage compared with silicon bipolar technology. Nevertheless, they are more expensive. The realization of radio frequency and Microwave circuits using silicon bipolar technology can provide good solution, which substantially reduces the cost. Furthermore, the advance in silicon bipolar technology process has made it more possible to realize radio frequency and microwave circuits with performance comparable to that using BiCMOS, GaAs, and CMOS. Most of the basic building blocks of a transmitter, such as Switch, Oscillators and Mixers, have been realized by silicon bipolar technology processes [1]-[7]. However, not much work has been done or reported on microwave PA with silicon bipolar technology due to the area size and difficult matching network impedance $(\mathrm{MN})$.

Matching impedances of the PA becomes one of the crucial parameters to be optimized for eliminate reflection wave that results in a decrease in energy consumption. However, matching impedances of the PA is degraded by growing output power. Matching impedance and output power are the main considerations when a class of PA is to be chosen. Different applications will result in different choices of PAs. Therefore, it has to understand the specifications of the PA in advance.

The PA are key element of a transceiver compared with other building blocks in full telecommunication system. Add to that, it is the main element remains responsible in terms of power 
consumption of the all transceiver system. Many circuit architectures commonly with the different technologies used for to design the power amplifiers have been proposed in literature [8]-[17]. Each of them presents a microwave power amplifier with BiCMOS, GaAs and CMOS topologies.

This paper presents, a novel design of microstrip microwave power amplifier is target for applications DCS at $1.80 \mathrm{GHz}$. This power amplifier consists of a silicon bipolar technology and it is improved by Collector-Feedback Bias configuration with a single power supply to achieve good performances at desired frequency.

The result of the paper is organized as follows: Section 2 presents the biasing methods, the schematic of proposed PA in detail is presented in Section 3, Section 4 presents the simulation results including a discussion and lastly, Section 5 offers the conclusion.

\section{BIASING METHODS}

Biasing is needed in a RF/Microwave power amplifier circuit to work with good performance, the DC bias condition of the RF/Microwave transistors is usually established independently of the $\mathrm{RF} / \mathrm{Microwave}$ design and ease to utilize are the principal concerns when choosing a bias configuration correctly.

There are several biasing techniques to feed an amplifier [18]. These are:

a. Fixed base bias

b. Collector-feedback bias

c. Dual feedback bias

d. Emitter-bias

e. Emitter feedback bias

f. Fixed bias with emitter resistor

g. Voltage divider bias

Among all Biasing Methods of microwave PAs, the Collector-feedback bias is the most attractive candidate in terms of high performance and circuit simplicity. The Collector-feedback bias configuration is used to design the proposed power amplifier at $1.80 \mathrm{GHz}$. Typically, This kind of biasing can operate with a single power supply and power losses smaller compared with other Methods of biasing.

The Collector-feedback bias as shown in Figure 1. In this circuit, the base resistor $\left(R_{B}\right)$ is connected through the collector and the base terminals of the transistor. This signifies that the base voltage, $V_{B}$ and the collector voltage, $\mathrm{V}_{\mathrm{C}}$ are inter-dependent owing to the fact that (1):

$$
V_{B}=V_{c}-I_{B} R_{B}
$$

From these Equations (2), (3). The Q-point (operating point) stays fixed regardless of the fluctuation in the load current. As seen for this type of biasing network that an increase in $I_{C}$ decreases $V_{C}$, which results in a reduced $\mathrm{I}_{\mathrm{B}}$, automatically reducing $\mathrm{I}_{\mathrm{C}}$.

$$
\begin{aligned}
& V_{C C}=\left(\mathrm{I}_{B}+\mathrm{I}_{C}\right) \mathrm{R}_{C}+V_{C} \\
& V_{C}=V_{C C}-\left(\mathrm{I}_{B}+\mathrm{I}_{C}\right) \mathrm{R}_{C}
\end{aligned}
$$

Note that:

$$
\begin{aligned}
& V_{C E}=V_{C} \\
& V_{B E}=V_{B} \\
& I_{C}=\beta I_{B} \\
& I_{E} \approx I_{C}
\end{aligned}
$$




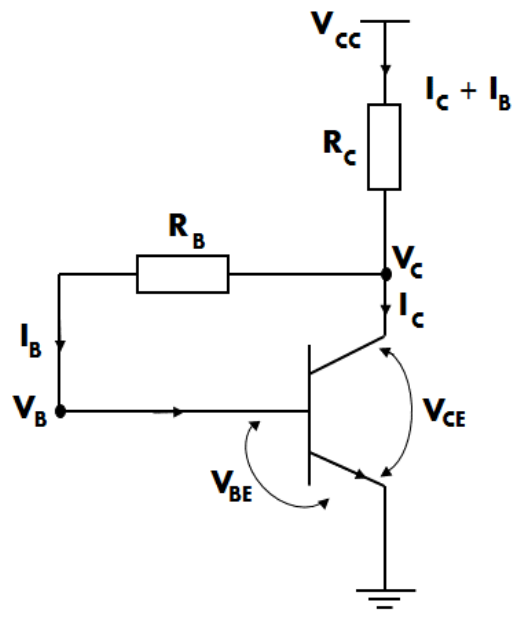

Figure 1. Collector-feedback bias circuit

\section{CIRCUIT DESIGN}

The proposed PA is designed with the Collector-feedback bias as illustrated in Figure 2. This amplifier is improved by microstrip transmission lines and with simple stubs to obtain a good performance in power gain with good matching impedances and high output power. A self-biased circuit (RF choke) is replaced by a high impedance quarter wavelength line $(\lambda / 4)$ with Radial stub connected in series for achieve proper isolation at desired RF frequency and Capacitors Cin and Cout at input and output stage is for DC blocking.

In this work, AT-41486 (Si BJT power transistor) die models from NPN with 4-terminal was chosen as the active device of the proposed PA. This transistor offers operating frequencies up to $10 \mathrm{GHz}$, maximum output power of $500 \mathrm{~W}, 12 \mathrm{Vdc}$ breakdown voltage. For low frequency of operation below than $10 \mathrm{GHz}, \mathrm{Si}$ BJT is a more suitable device technology compared to BiCMOS, CMOS or GaAs due to lower cost for mass fabrication. For the circuit design and simulation on PC using Agilent's Advanced Design System (ADS) software.

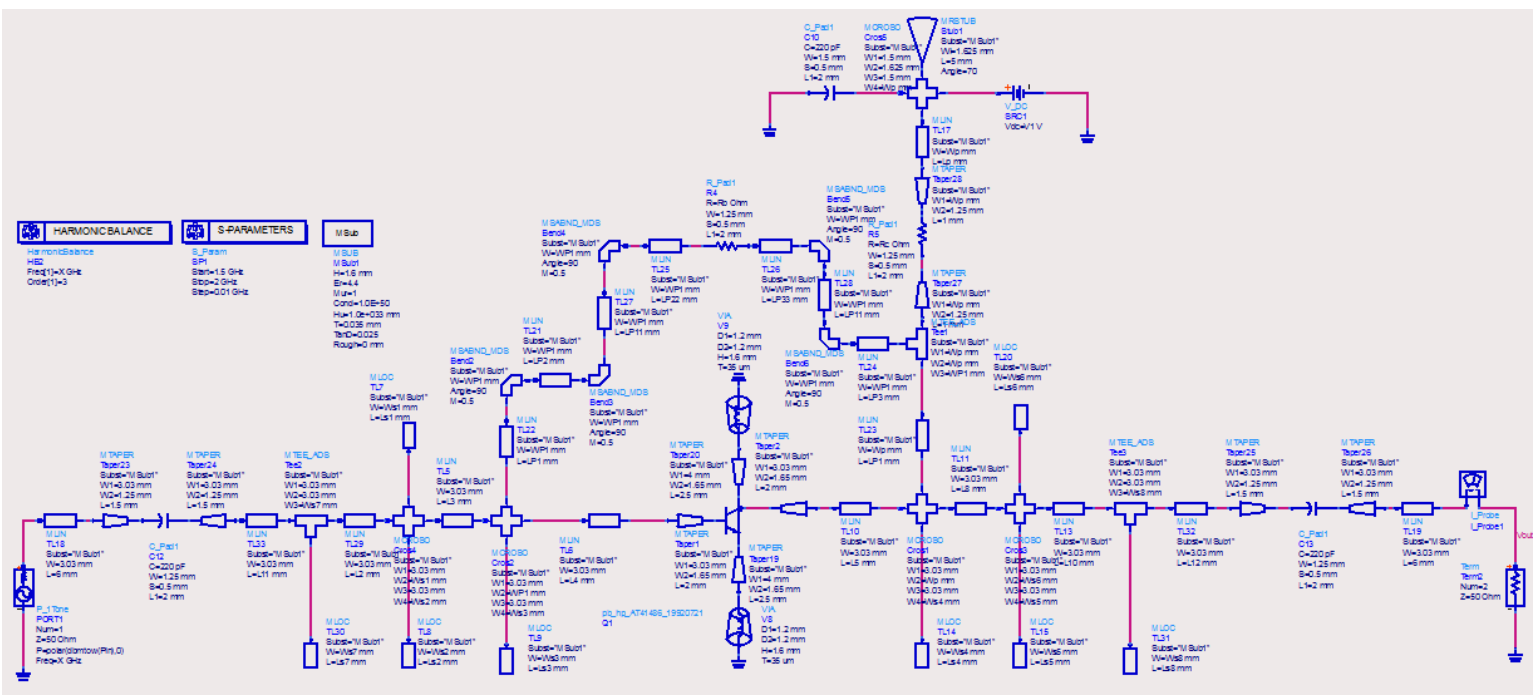

Figure 2. The Schematic of the proposed microwave amplifier

This power amplifier is printed on an FR4 substrate with a thickness of $1.6 \mathrm{~mm}$, a relative permittivity of 4.4 , a tangential loss of 0.025 and a metallization thickness $t=0.035 \mathrm{~mm}$. The proposed amplifier has an overall size of about $93 \mathrm{~mm}$ (L) $x 59 \mathrm{~mm}$ (W). Figure 3 shows the Layout for the designed PA. 


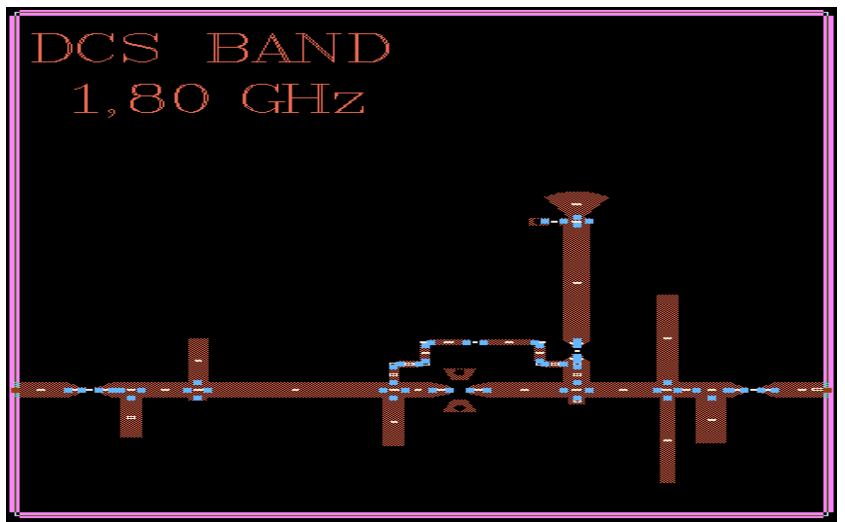

Figure 3. Layout of the validated power amplifier

\section{SIMULATION RESULTS AND PERFORMANCE ANALYSIS}

This section presents the simulated results of proposed microwave power amplifier operating at DCS band. It was implemented based on Agilent's Advanced Design System (ADS) software. From the simulation S-parameter. As can be observed, the proposed amplifier has $-46.39 \mathrm{~dB}$ input return loss (S11) and $-29.898 \mathrm{~dB}$ output return loss (S22) at $1.80 \mathrm{GHz}$. Figure 4 shows the simulated input/output return loss. While, the power gain $(\mathrm{S} 21)$ has a maximum value of $13 \mathrm{~dB}$ with a unilateral transmission coefficient (S12) less than $-19.5 \mathrm{~dB}$ in the operating frequency band.

The unilateral transmission (S12) is important to quantify in PA performance analysis as practically some signal transmitted back to the input from the output (Ideally should be no back reflection). This unwanted reverse signal interferes with fundamental signal flowing in forward direction from input to the output. In our proposed amplifier design, the input/output matching stage does not easily allow signals to propagate from the output to the input. Figure 5 shows the small-signal gain (S21) and the unilateral transmission (S12).

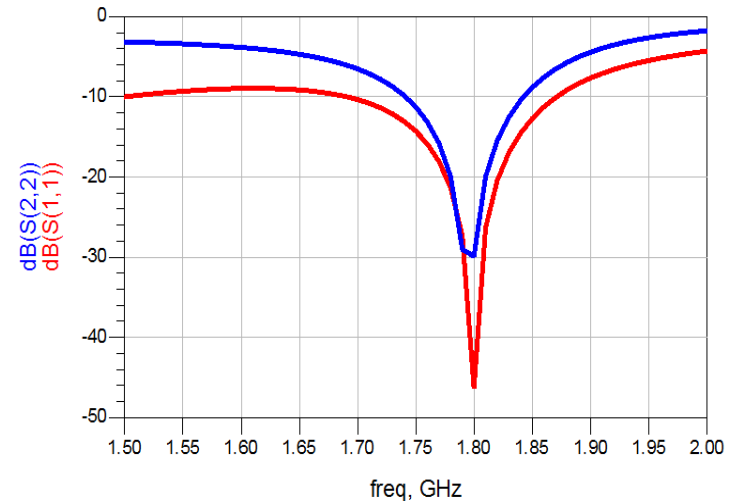

Figure 4. S1 1 \& S22 versus frequency of power amplifier

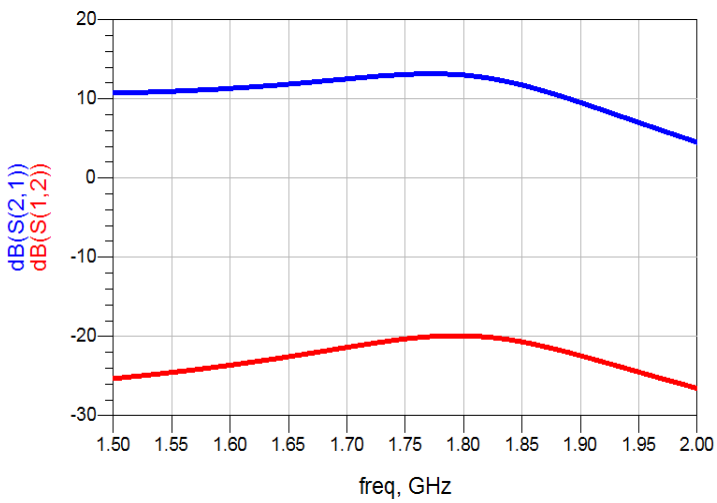

Figure 5. S21 \& S12 versus frequency of the proposed power amplifier

Stability test is very important in RF/Microwave power amplifier analysis as circuit might oscillate because of voltage variations at unexpectedly low or high frequencies. Specially, when there is a feedback path from output to input, the circuit might become unstable for certain combinations of source $\left(Z_{S}\right)$ and load impedances $\left(\mathrm{Z}_{\mathrm{L}}\right)$. According to Rolett Criteria as expressed by Equations (4) and (5) where $\mathrm{K}>1$ and $\mathrm{B} 1>0$ [18]-[20]. The circuit is unconditionally stable. To ensure stability over a wide range of frequencies, the stability was tested from $1.50 \mathrm{GHz}$ up to $2 \mathrm{GHz}$. Figure 6 and Figure 7 shows Stability Factor (K) is 1.33 and Stability measure (B1) is 0.795 Therefore, it can be said that amplifier is very much stable around $1.80 \mathrm{GHz}$ frequency range. 


$$
\begin{aligned}
& k=\frac{1-\left|\mathrm{S}_{11}\right|^{2}-\left|\mathrm{S}_{22}\right|^{2}+|\Delta|^{2}}{2\left|\mathrm{~S}_{12} \mathrm{~S}_{21}\right|}>1 \\
& B_{1}=1+\left|\mathrm{S}_{11}\right|^{2}-\left|\mathrm{S}_{22}\right|^{2}-|\Delta|^{2}>0
\end{aligned}
$$

$$
|\Delta|=\left|S_{11} S_{22}-S_{12} S_{21}\right|
$$

Where

$\mathrm{k}$ is the Rolett factor

$\mathrm{B} 1$ is the Stability measure

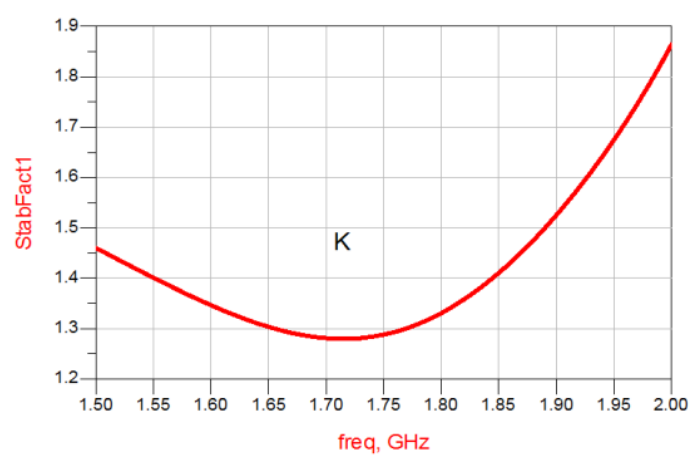

Figure 6. Stability factor versus frequency characteristics

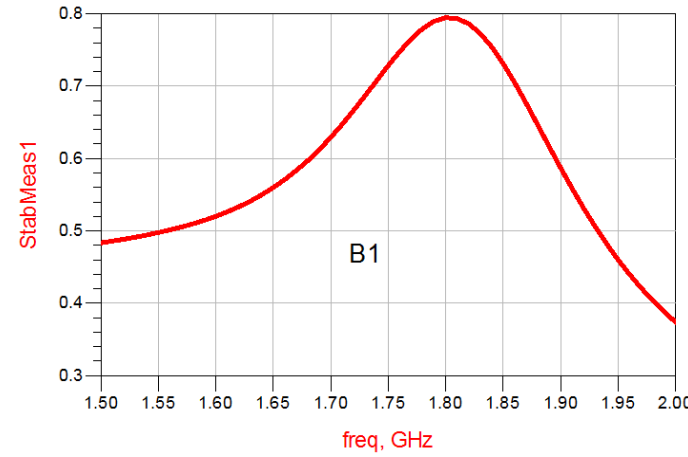

Figure 7. Stability measure versus frequency characteristics

Among all parameters indicated above as stability, power gain.

Output power is very important parameter for design the microwave power amplifier, generally to calculate the output power, the fundamental components of the load current and load voltage are take in consideration. Pout can be expressed by Equation (7) [18] and [19]:

$$
P_{\text {out }}=\frac{1}{2} \operatorname{real}\left(\mathrm{V}_{\text {out }} * \mathrm{i}_{\text {out }}^{*}\right)_{\mid f=f_{0}}
$$

As depicted in Figure below, this study was conducted for DCS applications at $1.80 \mathrm{GHz}$. For power input range from -30 to $30 \mathrm{dBm}$, the power amplifier exhibits a saturated output power of $21 \mathrm{dBm}$ and a P1dB of $19 \mathrm{dBm}$. Figure 8 show output power versus input power for $1.80 \mathrm{GHz}$.

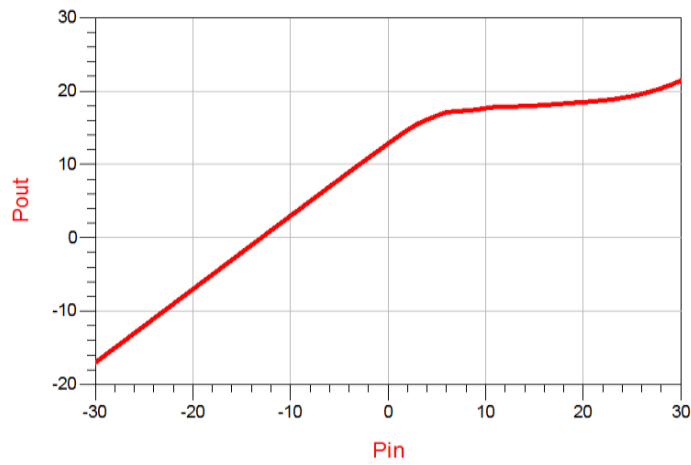

Figure 8. Output power versus input power for $1.80 \mathrm{GHz}$ 
Most of the reported design used different topologies and presented the results at different frequency band depending on intended applications. A comparison between the recently published works on state-ofthe-art of microwave amplifiers and the one proposed here is made. Table 1 summarizes the performance of the presented PA in comparison with other reported PAs. It can be observed that the proposed PA has highly Power Gain and good Reflection coefficients at the operating frequency band than other amplifiers, which verifies the results exhibit excellent performance of our design approach compared to the reported works.

Table 1. Performance Comparison with Recent Power Amplifiers

\begin{tabular}{cccc}
\hline Parameter & {$[21]$} & {$[22]$} & $\begin{array}{c}\text { The Proposed } \\
\text { PA }\end{array}$ \\
\hline Process & GaAs & $0.25 \mu \mathrm{m}$ & BJTs \\
& PHEMT & CMOS & \\
Frequency & 2.45 & $1.65-2$ & 1.80 \\
$\quad(\mathrm{GHz})$ & & & 13 \\
Power Gain (dB) & 7.51 & $5.1 \pm 0.5$ & -46.39 \\
$\quad \begin{array}{c}\text { Input Return } \\
\text { Loss }\end{array}$ & -7.497 & -14 & -29.89 \\
output Return & -10.950 & -19 & 19 \\
$\quad$ Loss & 14.01 & $18: 5$ & \\
P1dB (dBm) & & & \\
\hline
\end{tabular}

\section{CONCLUSION}

In conclusion, the design and analysis of a microwave power amplifier with a technology Microstrip has been presented. The simulation results show that the proposed amplifier offers an excellent performance for DCS applications at $1.80 \mathrm{GHz}$. The proposed design exhibits a power gain of $13 \mathrm{~dB}$ with reverse isolation less than-19dB under a 10V supply. The proposed power amplifier has successfully achieved and improved with good performance in terms of stability and matching impedance.This amplifier it is capable of delivering output power up to $21 \mathrm{dBm}$.

\section{ACKNOWLEDGEMENTS}

In this occasion, author would like to thankMr. Mohamed Latrach Professor in ESEO, engineering institute in Angers, France, for allowing us to use electromagnetic solvers available in his laboratory.

\section{REFERENCES}

[1] C.S. Tsai et al., "A VHF Oscillator Design Based on BJT Active Load Differential Amplifier”, IEEE Conference on Electron Devices and Solid-State Circuits, pp. 917-920, Tainan, 2007.

[2] G. Komanaplli, N. Pandey, R.Pandey, "New Realization of Quadrature Oscillator using OTRA", International Journal of Electrical and Computer Engineering (IJECE), vol. 7, no. 4, August 2017, pp. 1815-1823.

[3] S.T. Lim and J.R. Long, "A Low-Voltage Broadband Feedforward-Linearized BJT Mixer", IEEE Journal of SolidState Circuits, vol. 41, no. 9, pp. 2177-2187, Sept. 2006.

[4] M.J. Deen, D.S. Malhi, Z.X. Yan and R.A. Hadaway, "A New Mixer Circuit Using Gate-Controlled LPNP BJT", Circuits and Systems, 1995. ISCAS '95.IEEE International Symposium on, Seattle, WA, 1995, vol. 3, pp. 1968-1971.

[5] A. Nasri, H. Zairi, A. Gharsallah, "A Compact SIW Mixer for Millimeter-Wave Applications", International Journal of Electrical and Computer Engineering (IJECE), vol. 4, no. 6, December 2014, pp. 902-908.

[6] Nam-Jin Oh, "A Single-Stage Low-Power Double-Balanced Mixer Merged with LNA and VCO", International Journal of Electrical and Computer Engineering (IJECE), vol. 7, no. 1, February 2017, pp. 152-159.

[7] A.P. Arribas and M. Krishnamurthy, "SiC BJT Proportional Base Driver With Collector-Emitter Voltage Measurement and a Switching Regulator", IEEE Transportation Electrification Conference and Expo (ITEC), pp. 1-6, Dearborn, MI, 2016.

[8] C. Zhao, H. Liu, Y. Wu and K. Kang, "Analysis and Design of CMOS Doherty Power Amplifier Based on Voltage Combining Method", in IEEE Access, vol. 5, no. , pp. 5001-5012, 2017.

[9] J. Ko et al., "2.5 A high-efficiency multiband Class-F power amplifier in $0.153 \mu \mathrm{m}$ bulk CMOS for WCDMA/LTE applications", IEEE International Solid-State Circuits Conference (ISSCC), pp. 40-41, San Francisco, CA, USA, 2017.

[10] K.B. Maji, R. Kar, D. Mandal and S.P. Ghoshal, "Optimal Design Of Low Power Three-Stage CMOS Operational Amplifier Using Simplex-PSO Algorithm”, IEEE Region 10 Conference (TENCON), pp. 138-141, Singapore, 2016. 
[11] G.R. Basawapatna, "Design and Performance of a 2 to $18 \mathrm{GHz}$ Medium Power GaAs Mesfet Amplifier", 8th European Microwave Conference, pp. 458-462, Paris, France, 1978.

[12] K. Yamamoto, M. Hirobe, K. Iyomasa, M. Miyashita, S. Suzuki and H. Seki, "A Receive-Band-Noise Estimation Method and Its Application to a WCDMA Band 11/21 GaAs-BiFET MMIC Power Amplifier Module", IEEE Transactions on Microwave Theory and Techniques, vol. 64, no. 10, pp. 3244-3254, Oct. 2016.

[13] M. Li, C. Bildl, B. Schleicher, T. Purtova, S. Weigand and A. Link, "A co-designed Band 1-Band 3 carrier aggregation power amplifier quadplexer in GaAs-HBT and BAW technologies", IEEE MTT-S International Microwave Symposium (IMS) , CA, pp. 1-3, San Francisco, 2016.

[14] Hui Xu, Mimi Li, Yifang Xie and Yonghui Huang, "Design of X-band GaAs Power Amplifier", IEEE 6th International Symposium on Microwave, Antenna, Propagation, and EMC Technologies (MAPE), pp. 521-524, Shanghai, 2015.

[15] C. Chen, X. Xu, X. Yang, T. Sugiura and T. Yoshimasu, "A 20-30 GHz High Efficiency Power Amplifier IC With An Adaptive Bias Circuit in 130-nm SiGe BiCMOS”, IEEE 17th Topical Meeting on Silicon Monolithic Integrated Circuits in RF Systems (SiRF),pp. 88-90, Phoenix, AZ, USA, 2017.

[16] R. Wu, Y. Li, J. Lopez and D.Y.C. Lie, "A highly efficient watt-level SiGe BiCMOS power amplifier with envelope tracking for LTE applications”, IEEE Bipolar/BiCMOS Circuits and Technology Meeting (BCTM), pp. 1-4, Portland, OR, 2012.

[17] Y. Li, R. Wu, J. Lopez and D.Y.C. Lie, "A highly-efficient BiCMOS cascode Class-E Power Amplifier Using both Envelope-Tracking and Transistor Resizing for LTE-like Applications", IEEE Bipolar/BiCMOS Circuits and Technology Meeting, pp. 142-145 ,Atlanta, GA, 2011.

[18] David M. Pozar, "Microwave Engineering", Second Edition, University of Massachusetts at Amherst, John Wiely \& Sons, Inc., 1998.

[19] M. Steer, "Microwave and RF Design: A Systems Approach”, SciTech, Raleigh, N.C, 2010.

[20] E.L. Tan, "A Quasi-Invariant Single-Parameter Criterion For Linear Two-Port Unconditional Stability", IEEE Microwave and Wireless Components Letters, vol. 14, no. 10, pp. 487-489, Oct. 2004.

[21] A. Rasmi, A. Marzuki, M.R.C. Rose, I.M. Azmi and A.I.A. Rahim, "A $2.4 \mathrm{GHz}$ packaged power amplifier using GaAs PHEMT technology", IEEE Regional Symposium on Micro and Nano Electronics, pp. 148-151, Kota Kinabalu, 2011.

[22] H. Aniktar, H. Sjoland, J.H. Mikkelsen and T. Larsen, "A class-AB 1.65GHz-2GHz broadband CMOS medium power amplifier", pp. 269-272, NORCHIP, 2005.

\section{BIOGRAPHIES OF AUTHORS}
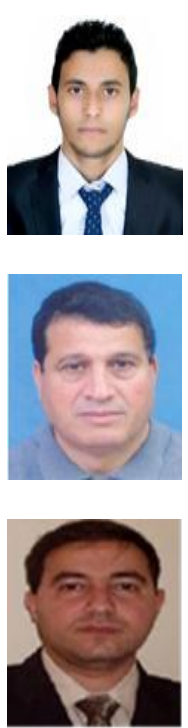

Amine Rachakh was born in Youssoufia, Morocco, in June 1990. He received the Master's degree in Microelectronics and Embedded Systems from the Faculty of Science Dhar El Mahrez, University Sidi Mohamed Ben Abdellah, Fes, Morocco, in 2014. He is currently prepared a Ph.D. degree in RF/Microwave and Electronics at Faculty of Sciences and Techniques, University Hassan 1st, Settat, Morocco, since 2015. His research interests include the study, design and realization of microwave power amplifiers.

Larbi El Abdellaoui was born in Tiflet, Morocco, in 1961. He received the Ph.D. degree in electronics from the University of Metz, in1994, France. He is currently an associate Professor of Electronics in Faculty of sciences and techniques, University Hassan 1st, Settat, Morocco. He is involved in the design of hybrid, monolithic active andpassive microwave electronic circuits.

Jamal Zbitou was born in Fes, Morocco, in June 1976. He received the Ph.D. degree in electronics from Polytech of Nantes, the University of Nantes, Nantes, France, in 2005. He is currently an associate Professor of Electronics in FST University Hassan 1st, Settat, Morocco. He is involved in the design of hybrid, monolithic active and passive microwave electronic circuits. 